\title{
Becoming Redundant: Australian Women's Experiences of Pregnancy After Being Unexpectedly Scheduled for a Medically Necessary Term Elective Cesarean Section
}

\author{
Sara Bayes, Jennifer Fenwick, and Yvonne Hauck
}

PURPOSE: There is now a comprehensive body of evidence reporting the effects of emergency cesarean section on women's emotional well-being. How women respond to becoming in need of a medically necessary elective cesarean section, however, has not previously been reported. This article describes and explains how a cohort of Australian women experienced the remainder of the antenatal period following the discovery during pregnancy of a medical reason to book a term elective cesarean section.

DESIGN: Grounded theory methodology was used for this study.

FINDINGS: Seven categories emerged from data analysis to represent the women's responses to becoming in need of a medically necessary term elective cesarean section. Four categories describe women's actions and interactions as they dealt with their lost expectations and their perceived "displacement" from their baby's birth. The other three categories represent the factors that mediated, or caused, women's responses.

MAIN CONCLUSIONS: This study provides new knowledge about how women experience and respond to an unwanted and unforeseen change in their childbearing journey. The sense of disappointment and loss that is likely to arise for women who must "change track" must be anticipated, recognized, acknowledged, and when possible, forestalled by maternity care professionals.

KEYWORDS: antenatal; loss; grief; psychosocial transition

\section{INTRODUCTION}

It can be assumed that for childbearing women, a healthy baby constitutes a "good" pregnancy outcome. In addition, although the experience of bearing their baby is also known to be of great importance for a woman's sense of self, which in turn affects her family's well-being (Brown \& Lumley, 1998; Callister, Holt, \& Kuhre, 2010; Parratt, 2002; Saurel-Cubizolles, Romito, Lelong, \& Ancel, 2000). A birth experience that is perceived by a woman to be positive and fulfilling is likely to imbue her with a sense of deep gratification and accomplishment. In contrast, an unhappy experience of childbirth is known to have a negative effect on women's biopsychosocial health, her relationships, and her family's functioning (Goodman, Mackey, \& Tavakoli, 2004; Hay et al., 2001; Mercer \& Marut, 1981; Sinclair \& Murray, 1998; Waldenström, Hildingsson, Rubertsson, \& Rådestad, 2004).

A number of factors are now recognized to be important for how women evaluate their childbearing experience. These include the attitudes and behaviors of caregivers, length of labor, level of distress, the occurrence and extent of complications, and involvement in decision making (Adewuya, Ologun, \& Ibigami, 2006; Domingues, Santos, \& Leal, 2004; Goodman et al., 2004; Harriott, Williams, \& Peterson, 2005; Hodnett, 2002; Howell-White, 1999; Lundgren, 2005; Maggioni, Margola, \& Filippi, 2006). One of the predominant 
drivers of women's satisfaction with their childbearing experience, however, seems to be the extent in which their expectations were met (Christiaens \& Bracke, 2007; Soet, Brack, \& Dilorio, 2003).

According to research, a natural labor and birth is among the priority expectations held by most women (de Oliveira, Riesco, Miya, \& Vidotto, 2002; Fenwick, Gamble, \& Hauck, 2006; Fenwick, Hauck, Downie, \& Butt, 2005; Gamble \& Creedy, 2001; Ip, Chien, \& Chan, 2003; Kao, Gau, Wu, Kuo, \& Lee, 2004; Oweis \& Abushaikha, 2004; Rijnders et al., 2008). Despite this, estimates suggest that one fifth of childbearing women across the developed world (Betrán et al., 2007) and approximately one third in Australia (Laws, Li, \& Sullivan, 2011) have a cesarean section. There is a comprehensive body of evidence describing the psychological and emotional implications for women who have an unanticipated "nonelective" or emergency cesarean section (e.g., Herishanu-Gilutz, Shahar, Schattner, Kofman, \& Holcberg, 2009; Ryding, Wijma, \& Wijma, 1998; Somera, Feeley, \& Ciofani, 2010); however, knowledge about how women experience a medically necessary elective cesarean section that they were not originally expecting has not previously been reported. The study reported in this article, which asked "how women experience becoming in need of and anticipate giving birth by elective cesarean section for a medical reason that emerged during pregnancy" sought to address this gap.

\section{METHODS}

\section{Design}

This study was conducted using the original ("Glaserian") variant of grounded theory (Glaser \& Strauss, 1967). The purpose of this methodology is to enable the development of a theory that conceptualizes the meaning of experience and behavior (Sidani \& Sechrest, 1996). The overall aim of a grounded theory is to explain "what is going on" from the participants' perspective (Glaser, 1998, p. 25).

\section{Setting and Participants}

The setting for this study was an Australian tertiary level maternity hospital located in the center of a state capital city. During the period of data collection, approximately 5,500 births occurred at the hospital per year. At this time, on the average, 34 of the 460 or so births each month were by scheduled cesarean section at term (between 37 and 42 completed weeks of pregnancy). Two groups of participants were recruited for this study: pregnant women who had been advised that they would need to give birth by elective cesarean section and maternity health professionals (MHPs) who cared for women in this situation. The women represented the study's key informants, whereas the data provided by the MHPs was used to illuminate (i.e., confirm and contextualize) that obtained from the women. Recruitment of all participants was by both purposive and theoretical sampling methods and continued until saturation of the women's data was attained.

\section{Recruitment of Women}

Most women $(n=25)$ were approached and recruited from the hospital's cesarean section "preadmission clinic" (PAC); the remainder $(n=3)$ self-selected after seeing posters advertising the study in the hospital public areas. Women were eligible for inclusion in the study if they were having a first cesarean section for a medical reason, could speak English, and were older than 18 years of age. Interested women were given an information sheet and asked if the researcher might telephone to see if they would be willing to participate. A contact number was obtained for those who agreed.

\section{Recruitment of Maternity Health Professionals}

The MHPs including medical staff, nurses, midwives, and anesthetists' assistants were recruited through "in-service" information sessions about the study. All MHPs who agreed to participate were interviewed, and recruitment of this sample ceased when this data set was saturated. Verbal informed consent to participate was obtained from all participants and was subsequently confirmed in writing at the time of interview.

\section{Data Collection}

Three forms of data were collected for this study, which was conducted between October 2006 and March 2008 (see Table 1).

\section{Semistructured Interviews With Women}

The first interviews with women were held between 4 and 48 hours prior to women having their cesarean section, the average time being 18 hours. Second interviews with these women were conducted at between 10 and 14 weeks postpartum and lasted an average of lhour 
TABLE 1 Summary of Data Collection in Hours and Minutes

\begin{tabular}{lcc} 
DATA COLLCTION & N & $\begin{array}{l}\text { HOURS/MINUTES } \\
\text { OF DATA }\end{array}$ \\
\hline $\begin{array}{l}\text { Interviews with women }(2 \times 28) \\
\text { Interviews with maternity health } \\
\quad \text { care professionals }\end{array}$ & 56 & $101 / 44$ \\
Field notes & & $17 / 35$ \\
& - & $41 / 55$ \\
\hline
\end{tabular}

and 49 minutes. The interviews comprised open-ended questions and were structured to encourage women to work backward temporally through their original expectations for this pregnancy to their earliest impressions, recollections, and expectations of childbirth. Additional questions were added to interviews as data analysis progressed.

\section{Semistructured Interviews With Maternity Health Professionals}

Interviews with MHPs, which were held within the hospital setting and lasted an average of 39 minutes, also comprised open-ended questions, for example, "How do you imagine women feel about needing to have a scheduled cesarean section?" and "Describe how you care for a woman who needs a scheduled cesarean section." As with the women's interviews, additional questions were asked of the MHPs as data analysis progressed.

\section{Researcher Field Notes}

In addition to interview data, field notes were made during this study. These comprised the researcher's perceptions, thoughts, and feelings before and after each interview, and featured the researcher's impressions of the antenatal clinic environment, observations and thoughts arising during participant recruitment, and the thoughts raised during formal interviews. The field notes also provided annotated records of informal conversations with MHPs, women and their families, relevant exchanges with friends, acquaintances and family members, and summaries of news and other journalistic items of interest.

\section{Ethical Considerations}

Both the university and hospital human ethics research committee's approval to conduct the study was granted.

\section{Data Analysis}

The analysis of data obtained from the semistructured interviews adhered to the principles, underlying logic, and procedures originally set down by Glaser and Strauss (1967) and later expounded by Glaser (1978). The process of arriving at the outcome of a grounded theory study is not linear, but iterative. The researcher moves forward and backward between data collection, data analysis, and theory generation. All stages are performed simultaneously and reflexively within this "constant comparison" method (Flint, 2005; Glaser \& Strauss, 1967). This process involved the systematic reduction of the data into codes, which were then grouped into seven major categories, two of which comprise more than one dimension.

\section{Trustworthiness}

Among the criteria by which the worth of a qualitative investigation is evaluated are how vividly and faithfully the phenomenon is represented and the degree to which the findings can be traced as trustworthy (Carpenter Rinaldi, 1995). Cho and Trent (2006) assert that these qualities might be assessed in terms of either transactional or transformational trustworthiness (p. 320). The transactional approach involves interaction between the researcher and the research participants by the use of such measures as member checking and triangulation. In member checking, findings are presented back to informants to check for perceived accuracy (Cho \& Trent, 2006, p. 322). Triangulation, or the use of multiple sources (Denzin, 1989, p. 236), provides a means of deriving a more consistent, objective picture of reality than would a single source (Cho \& Trent, 2006, p. 323). Triangulation may be attained by drawing on different types of data and/or multiple investigators' interpretations of the data (Golafshani, 2003). Transformational validity, meanwhile, is determined by the resultant actions prompted by the research endeavor (Cho \& Trent, 2006, p. 324).

Trustworthiness in this study was pursued through both transactional and transformational approaches. Data were triangulated by the collection of interview data from health care professionals and from investigator field notes as well as from women themselves. Investigator triangulation was sought through informal and formal discussion and debate among the research team around the emerging theoretical concepts and categories as they arose. Recognition and accuracy of the emerging theoretical rendition was also provided on a number of occasions both from women who had experienced 
becoming unexpectedly obliged to book a medically necessary cesarean section during pregnancy and from health professionals who cared for this group of women.

On two occasions, the data was presented to women who were members of the community group "Birthrites: Healing After Cesarean." Both sessions were well attended by 26 women, in whom the study findings evoked deeply emotional responses as they confirmed their own experiences. In response to the data attendants at the sessions repeatedly said, for example, "that is exactly what it's like," "that is just how it feels," and "that's what happened to me." The emerging findings were also presented at several time points at a number of professional study days and conferences, including a national midwifery conference and an international midwifery congress (Bayes \& Dufton, 2008; Bayes, Dufton, \& Nunan, 2009; Bayes, Fenwick, \& Hauck, 2007, 2008). Audiences at each included maternity care consumers, doctors, and midwives, among whom the findings evoked strong emotional responses. Some women cried, and many came to speak with us at length afterward to tell us how strongly reminiscent of their experience the data was. The work also seemed to resonate with health professionals' experiences of caring for this group of women; an example of this occurred at one conference when an obstetrician stood, spoke of the findings as "truly eye opening," and initiated a standing ovation. Such reactions to this work provide clear confirmation that the findings do vividly and faithfully represent the phenomenon.

Further affirmation of the trustworthiness of these findings is demonstrated by the maintenance of records pertaining to theoretical decision making and development. Wolf (2003) suggests that an audit trail, or "confirmability" audit might include, for example, evidence of the "details of data analysis and some of the decisions that led to the findings" (Wolf, 2003, p. 175). Finally, in transformational terms, both the location of the study in the clinical areas of the hospital and the study findings engendered a number of clinical practice changes, which are described in the conclusion section of this article.

\section{RESULTS}

Data were collected from 28 women and 22 MHPs. The women participants were aged between 23 and 41 years and from diverse cultural and social backgrounds. Eight women were having their first baby, whereas the remaining 20 had between one and four children already. Demographic and other details of participant women are provided in Table 2. The MHP group included eight
TABLE 2 Details of Participant Women $(n=28)$

\begin{tabular}{|c|c|c|}
\hline CHARACTERISTIC & FREQUENCY & $\%$ \\
\hline \multicolumn{3}{|l|}{ Age (years) } \\
\hline $20-25$ & 9 & 32 \\
\hline $26-30$ & 10 & 36 \\
\hline $31-35$ & 3 & 11 \\
\hline $36-40$ & 5 & 18 \\
\hline $41-45$ & 1 & 4 \\
\hline \multicolumn{3}{|l|}{ Ethnicity } \\
\hline White Australian & 15 & 54 \\
\hline Australian Aboriginal & 1 & 4 \\
\hline White European & 4 & 14 \\
\hline Indian & 2 & 7 \\
\hline New Zealander & 2 & 7 \\
\hline Chinese & 1 & 4 \\
\hline Japanese & 1 & 4 \\
\hline Vietnamese & 2 & 7 \\
\hline \multicolumn{3}{|l|}{ Previous live births } \\
\hline 0 & 8 & 29 \\
\hline 1 & 13 & 46 \\
\hline 2 & 5 & 18 \\
\hline 3 & 1 & 4 \\
\hline 4 & 1 & 4 \\
\hline \multicolumn{3}{|l|}{ Educational background } \\
\hline Did not finish high school & 2 & 7 \\
\hline Finished compulsory education & 8 & 29 \\
\hline $\begin{array}{l}\text { Completed further education to } \\
18 \text { years }\end{array}$ & 7 & 25 \\
\hline Completed university degree & 9 & 36 \\
\hline Completed higher degree & 2 & 7 \\
\hline \multicolumn{3}{|l|}{ Occupation } \\
\hline Unemployed, no children & 3 & 11 \\
\hline "Stay-at-home mom" & 7 & 25 \\
\hline Studying full time & 1 & 4 \\
\hline Studying part time & 2 & 7 \\
\hline Working full time & 8 & 29 \\
\hline Working part time & 9 & 32 \\
\hline Service position & 7 & 25 \\
\hline Professional position & 10 & 36 \\
\hline \multicolumn{3}{|l|}{ Household income } \\
\hline AU\$0-AU\$15,000 & 3 & 11 \\
\hline AU\$15,001-AU\$30,000 & 1 & 4 \\
\hline AU\$30,001-AU\$45,000 & 4 & 14 \\
\hline $\mathrm{AU} \$ 45,001-\mathrm{A} \cup \$ 60,000$ & 3 & 11 \\
\hline AU\$60,001-AU\$75,000 & 12 & 43 \\
\hline $\mathrm{AU} \$ 75,001-\mathrm{A} \cup \$ 100,000$ & 4 & 14 \\
\hline $\mathrm{A} \cup \$ 100,001-\mathrm{A} \cup \$ 125,000$ & 1 & 4 \\
\hline
\end{tabular}

midwives, four operating room nurses, seven doctors (including three obstetricians, three anesthetists, and one neonatologist), and three anesthetic technicians. One hundred and nineteen hours of interview data were collected from these two groups. In addition, 42 hours 
of field notes were recorded and contributed to the analysis (see Table 1).

\section{"Becoming Redundant"}

Seven major categories emerged from the data to describe and explain the women's experiences of and responses to needing a medically necessary cesarean section. Together, these were presented under the core category of becoming redundant. Four major categories describe how the need for and decision to schedule an elective cesarean section affected the women and how they dealt with it (see Table 3). The remaining three major categories represent factors that moderated or explained their responses (see Table 4). Category and subcategory labels appear in single inverted commas, and direct quotes appear in double speech marks. All names used are pseudonyms.

\section{"Feeling Robbed"}

The major category that represented women's experience of being told they would need a scheduled cesarean section was labeled feeling robbed. Receiving the news destabilized women and was often accompanied by an intense physical reaction. For example, women variously described feeling "unbalanced," "giddy," "spun out," "completely floored," "gutted," and "out of whack." Fiona's description of "being knocked sideways" and Madeleine's comment of having the "rug pulled out from under me" were examples of analogies women used to explain the shock they felt. Women spoke of their imagined natural birth being "coldly" and "callously," "seized," or "stolen" by the need for

TABLE 3 Major Categories and Subcategories Under the Core Category of Becoming Redundant

\begin{tabular}{|c|c|c|}
\hline SUBCATEGORIES & $\begin{array}{l}\text { MAJOR } \\
\text { CATEGORIES }\end{array}$ & $\begin{array}{l}\text { CORE } \\
\text { CATEGORY }\end{array}$ \\
\hline $\begin{array}{l}\text { Making sure a cesarean's } \\
\text { really necessary }\end{array}$ & Feeling robbed & \\
\hline $\begin{array}{l}\text { Broadcasting the news } \\
\text { Searching for information }\end{array}$ & $\begin{array}{l}\text { Trying to make } \\
\text { it feel real }\end{array}$ & \\
\hline & $\begin{array}{l}\text { Becoming a per- } \\
\text { sona non grata }\end{array}$ & $\begin{array}{l}\text { Becoming } \\
\text { redundant }\end{array}$ \\
\hline $\begin{array}{l}\text { Trying to make the best } \\
\text { of it } \\
\text { Rehearsing }\end{array}$ & $\begin{array}{c}\text { Travelling a new } \\
\text { path blindly }\end{array}$ & \\
\hline
\end{tabular}

\section{TABLE 4 Major Categories Representing Mediating Factors}

Expecting birth would be natural

Cesarean section is hospital not women's business

Hurtling toward d-day

cesarean section and personified the cesarean section as a "thief" that as Stephanie said, "took [sic] my birth off me." The cesarean section was also perceived to "take" the "specialness," "joy," and "magic" of having a baby. In addition, the participants described how the news engendered terror, fear, and anxiety and in essence "haunted" them, robbing them of their confidence. Women also felt robbed of their autonomy as having to have a cesarean section meant having no control over the situation or their bodies.

\section{"Trying to Make it Feel Real"}

Once the women had recovered their composure a little, they began trying to adjust to their new reality and engaged in trying to make it feel real. This major category comprised three subcategories that together provide an indication of just how much emotional work was involved for women in understanding and dealing with their changed circumstances.

"MAKING SURE A CESAREAN'S REALLY NECESSARY": This first subcategory involved women trying to verify that the decision to schedule a cesarean section was "right." To begin with, women described having to be convinced that there was no real option but to have one. They did this in a number of ways, for example, by seeking other professional opinions both within and outside of the institution, requesting repeated diagnostic investigations and examinations, and seeking nonprofessional peer guidance and opinion from Internet forums. For example, on being told of the need for a cesarean section after an ultrasound scan showed her placenta was covering her cervix, Steph's first response was to "ask for another scan a week later, before [she] signed on the dotted line." Similarly, when Jan got home from the hospital where she was told that she wouldn't be able to have a natural birth, she telephoned to request an urgent appointment to discuss the decision with a different doctor. Several women also described seeking opinions and advice from Internet communities that they had become part of, such as pregnancy chat rooms. 
"BROADCASTING THE NEWS": The second subcategory of trying to make it feel real represents women's decision to disclose their need for a cesarean section to others as a way of helping them realize and integrate their new reality. The data suggests that broadcasting the news was primarily about women trying to make it "sink in." As Madeleine said, "I think sharing it with people, that's what really brought it home to me." However, women did feel some apprehension about sharing the news with their wider family. For the most part, families reacted with empathy, compassion, and encouragement. Some families though, did not respond so favorably or in line with women's responses. Julia, for instance, said that her family was so accepting that they were "almost smug about it." She said that her three sisters, who all had cesarean sections for a range of reasons, gave her the impression that they thought she was overreacting. Julia said she felt that they "did not get-at all—why I wouldn't be pleased or relieved." As a result, although broadcasting their news did help the need for a cesarean section to sink in, incongruity between women's own and their loved ones' responses left them feeling very alone, isolated, and with no one to talk about how they were feeling.

"SEARCHING FOR INFORMATION": The third subcategory describes women's desperate efforts to try and find out about how having a cesarean section would be like and how they could expect to feel during the procedure. Specifically, women desired a subjective, personal, and experiential perspective on the procedure. This yearning was exemplified by many quotes in the data set but perhaps best captured by Anne when she said, "It's not enough to just know what's going to be done, I want to get a feel for it [holds both hands up, makes grasping movements]. You know, how do you feel [original emphasis] when it's going on?" Ultimately, however, their search proved virtually fruitless. Women articulated that the little information they did find on scheduled cesarean section almost exclusively described the procedure from a "cold" or "clinical" viewpoint, and although this type of information was of some interest, it was inadequate.

\section{"Becoming a Persona Non Grata"}

As the initial shock of the decision subsided, women soon began to feel that their individual needs were displaced by a focus on the logistics of planning their elective cesarean section. In essence, women perceived that MHPs prioritized the "needs of the procedure" over women's own needs. They noticed, for example, that the focus of the hospital staff's concern shifted away from the woman herself and onto the "paperwork" and "tests" related to the cesarean section; this was women's experience even when there were several weeks left before their cesarean section date. Women nostalgically conveyed how their prior antenatal care had included staff investing time, energy, and enthusiasm into progressively preparing them for the day when they would labor and give birth to their baby and how this changed abruptly after the decision for cesarean section was made. Janine recalled, "They used to ask how I was, did I have any questions et cetera [sic], and really seemed to want to know. It's not really like that now." Women described that although staff remained polite, they became cooler, more distant, less interested in them personally and solely focused on physiological measures and tasks to be completed in preparation for the operation. Becoming "invisible" and "kept at arm's length" were common descriptions in the data set. Becoming passive recipients of care left women feeling like "bystanders" or "second-class citizens" in their journey toward childbirth. Additionally, the shift in caregivers' focus resulted in women never being afforded an opportunity to disclose or explore their feelings about needing a cesarean section.

\section{"Travelling a New Path Blindly"}

In response to having had their "job" taken by the need for a cesarean section and to neither receiving nor finding any guiding information about having one, women set about trying to prepare for the procedure as best as they could. Composed of two subcategories, this major category represents the preparation strategies employed by women as they awaited their cesarean section.

"TRYING TO MAKE THE BEST OF IT": The first subcategory of travelling a new path blindly conveyed how women actively decided to downplay the disappointing and frightening aspects of a scheduled cesarean section and chose instead to look for good things about the situation. In many cases, women revised their thinking on features of cesarean section they had originally considered negative and turned them into "plus points." Participants talked about "putting a positive spin" on having a cesarean section and tried to work out how it could be a good and fulfilling experience as well as what they could possibly usefully contribute. The perceived benefits of the intervention that appeared in the data included knowing exactly when the baby would arrive, feeling it would be less stressful for partners, having a 
longer postpartum stay in the hospital, having the baby in the daytime so visitors could be accommodated, not having any labor pain, and knowing the procedure would be calm and controlled. Interestingly, many of these perceived advantages were also reasons women cited for not wanting a cesarean section earlier in their interview; when first faced with the prospect of an elective cesarean section, women spoke, for example, of how knowing exactly when the baby would arrive had meant that the "mystery" and "excitement" that went along with waiting for labor to begin was lost to them. Similarly, no longer having the opportunity to experience labor pain was described initially to have been extremely disappointing.

"REHEARSING": The second subcategory comprises data about women's efforts to deal with their fear, terror, and anxiety. Women described trying to envisage how they might feel, what they might be thinking about, and how they would behave during the surgery. They did this continually in an attempt to become clear about what would take place. Trinny, for example, said she had "run through it a lot in [her] mind, trying to get a feel for what it would be like." Despite spending a lot of time mentally rehearsing the cesarean section, women found it very difficult to clearly determine what their role would be in the operating theater. By the time the day came around, the only decision all women had made about what they could usefully do during the procedure was, simply, to keep as still and silent as possible. Jan's comment was typical. She said,

I have thought it through and thought it through, and I just can't see there is anything for me to do. Except just literally lay there. It's all gonna be taken care of by [the staff]. There will be literally nothing for me to do.

Women only planned to invoke this state of "suspended animation," until their baby was born though, after which they intended to begin, as Fleur said, "being the baby's mother."

\section{Mediating Factors}

Three major categories were conceptualized as mediating factors emerged from the data that mediated and influenced (Vogt, 1993) women's response to needing a cesarean section.

\section{"Expecting Birth Would be Natural"}

The first factor that served to mediate women's responses to needing a scheduled cesarean section was the participants' expectation that their baby's birth would be a spontaneous natural event-"I thought it would just all happen as nature intended" (Julia). Contributing to their attitude on birth mode was the women's belief that natural or vaginal birth was best for their baby. The women articulated an understanding that vaginal birth conferred benefits to the baby such as "good hormones" and the importance of "going through the birth canal" on initiation of respiration. Many of the women indicated that they thought the shared experience of labor and birth would strengthen their connection with their baby. In addition, several women believed that giving birth naturally would leave them with a sense of achievement and fulfillment. Laboring and giving birth vaginally was identified by the women as a personal growth experience that held significant meaning and importance in their lives. They spoke of giving birth naturally as "a test of character," "an arduous trial," which promised an "opportunity for deep transformation" that "turns you into a real woman." Kate, for example, identified laboring and giving birth naturally as a rite of passage, clarifying, "it's a woman's rite . . . I mean as in 'r. i. t. e.' rite, not 'r. i. g. h. t.', although I suppose it's that too."

\section{"Cesarean Section Is Hospital Not Women's Business"}

Women's reactions to the news that they would need an elective cesarean section was also mediated by their perceptions that staff now regarded their birth as a surgical procedure that "belonged" exclusively to the hospital rather than to women. Analysis of contextual data (field notes, observations, health care professional interviews, literature given to women about cesarean section, and clinical guideline documents) demonstrated that cesarean section was considered by the hospital to be a routine surgical intervention and not women's business. Typically, women were referred to as "preop," "postop," or "surgical patients" or "cases" and no role, other than one of passivity, was ascribed to them by the hospital. Once women were scheduled for cesarean section, they were excluded from several antenatal birth preparation activities such as attending antenatal classes, visiting the area where their baby would be born, and writing a birth plan. Such exclusion alerted and reinforced women's sense of being deposed and made redundant by the cesarean section. 


\section{"Hurtling Toward D-Day"}

Women's "success" at adapting to and "working with" the need for a cesarean section during the remainder of their pregnancy was mediated by a third factor, which was the fact that the date for their procedure was set and as Dee described it, "looming large." Regardless of how much time women had between receiving the news that they would need a scheduled cesarean section and actually having it, the available time was not enough to fully integrate the decision. For some women, the time they had to come to terms with the change of plan was very short indeed, only 2 or 3 days, whereas the longest a woman had to come to terms with the news and prepare herself was 5 weeks. As Adrienne said,

I imagined it like a giant, I don't know, stick man or something ... in the distance that got bigger the closer it came. Coming towards me [raises arms, makes hands into claws]. It's like it's coming, ready or not.

The less time women had available to them, the more rushed, superficial, and incomplete their preparation endeavors were felt to be. This meant that women went into their cesarean sections still feeling confused, uncertain of its necessity, and with many unanswered questions about what would take place and how they would feel.

\section{DISCUSSION}

A limitation of this study was that only women who could speak conversational English and those who were older than 18 years of age could participate. The inclusion of women younger than 18 years old and those who were unable to speak English would have enabled further substantiation of the emergent theory. Despite this limitation, however, the remit of this study, which was to generate a theory of how women experienced the remainder of their pregnancy after unexpectedly learning they would need a cesarean section at term, was fulfilled. Generalizability is not the focus of grounded theory research; the rich description of the context and findings of this study will, however, enable the reader to determine its relevance and transferability to the context of the maternity system in their own country of practice.

For the women in this study, becoming in need of and awaiting a scheduled cesarean section was a frightening and disempowering experience that shattered long-held expectations and triggered a sense of becoming redundant. Becoming no longer able to give birth naturally meant that women lost great many aspects of their childbearing experience, perhaps most importantly of which was their own centrality. All of the women set about trying to recapture this and their other losses where they could; however, several factors hampered their ability to deal with and transition to their new reality.

Women's journey to becoming redundant began when they discovered that a cesarean section would be necessary, which was at odds with their childbirth expectations. Consistent with previous research, our participants entered into pregnancy with a belief that they would labor and birth naturally and that, although challenging, birthing their baby would represent a positive life event (de Oliveira et al., 2002; Fenwick et al., 2006; Fenwick et al., 2005; Gamble \& Creedy, 2001; Ip et al., 2003; Kao et al., 2004; Oweis \& Abushaikha, 2004). In relation to this primary expectation, the women also anticipated they would "own" their birth experience. The disappointment and distress the women in this study experienced was a direct consequence of no longer being able to fulfill their childbirth expectations.

According to psychiatrist Colin Murray Parkes (1993, p. 102), when radical change is experienced, the opportunity to fulfill our expectations dies, and what we experience is the perceived loss of our entire "assumptive world." Parkes (1971) introduced the concept of the assumptive world in the early 1970s and described it as including "our expectations of the future, our plans and our prejudices" (p. 102). When the theory is applied to this study, it becomes clear how women felt the need for an unwelcome cesarean section robbed them of the potential to fulfill their childbirth expectations and own their birth experience.

\section{Loss of the Opportunity to Give Birth Naturally}

The participants' expectation that they would give birth confirms mounting evidence that most women would prefer a spontaneous vaginal birth than a cesarean section despite continued media and medical debate to the contrary. In their review of 10 papers on the subject of "maternal request" cesarean section published between 1993 and 1999, Gamble, Creedy, McCourt, Weaver, and Beake (2001) concluded that the proportion of women wishing a cesarean section in the absence of previous or current obstetric complications was less than $1 \%$. Subsequent reviews and meta-analyses of similarly themed 
studies have confirmed that even in the presence of previous or current obstetric complications, cesarean section is the preferred birth mode for no more than $15 \%$ of women internationally (Mazzoni et al., 2011; McCourt et al., 2007).

\section{Loss of Role and Responsibility for Birth}

According to Luyben and Fleming (2005), being able to bear the responsibility of childbearing is of fundamental importance to pregnant women. Unfortunately, as soon as the decision was made that a cesarean section would be scheduled, the women in this study reported that from that point on, hospital care and communications were underpinned by a presumption that "the system" was now responsible for the baby's birth. Although loss of control during childbearing has been extensively documented, for the most part, this has only been in relation to the role that control plays in women's postpartum reflections of satisfaction with their birth experience (Fair \& Morrison, 2011; Fowles, 1998; Goodman et al., 2004; Simkin, 1991), is predominantly concerned with natural birth, and quite clearly demonstrates an association between the inability to retain a perception of personal power and control and a negative birth experience.

Involvement in intrapartum decision making is a key correlate to feeling in control during the event. In turn, having felt in control while giving birth is an important characteristic of a positive birth experience and feeling satisfied with the event (Fair \& Morrison, 2011; Lavender, Walkinshaw, \& Walton, 1999; Schneider, 2002; Waldenström et al., 2004, p. 23). As previously stated, to date, the negative implications for women of having not felt in control during childbirth are predominantly described in the context of natural birth (Fair \& Morrison, 2011); no research seems to exist concerning loss of control in relation to becoming unexpectedly in need during pregnancy of a term scheduled cesarean section. When the experience of the women in this study is considered in the light of the convergent literature, however, it is little wonder that they felt a sense of loss once their role and ability to control their experience was usurped.

\section{Loss of the Opportunity to Complete Certain Rites of Childbearing}

The women participating in this study were neither unable to find any information about the personal experience of having a scheduled cesarean section nor were they able to participate in the same birth preparation activities that women anticipating a vaginal birth were. Midwife theorist Rubin's early work around maternal identity and maternal tasks of pregnancy sheds some light on why needing to "get to know" scheduled cesarean section in these ways might have been important to women and why being unable to do so engendered a sense of loss.

Rubin (1976) argues that the motivational behavior of pregnant women is based on four interdependent goals. The first of these is to seek safe passage for herself and her child through pregnancy, labor, and delivery and involves engaging in various protective behaviors in relation to her own personal safety and that of her baby, including seeking many forms of information and care that will minimize threat or harm (p. 370). The information-seeking behavior examples that Rubin gives include reading books and magazines, watching films and television programs, talking with other women deemed as having expertise in childbearing, and consulting with maternity care professionals. Although the women in this study were able to access a limited amount of information, it in no way met their needs. The inability to find information they perceived as useful in building their "picture" of and contribution to scheduled cesarean section meant women could not fully assure themselves that their own and their baby's birthing passage would be a safe one.

\section{CONCLUSIONS AND RECOMMENDATIONS}

When considered in the context of existing literature and theory, the findings of this investigation have important implications for the care of childbearing women. This study provides new knowledge about how women feel and respond when their childbearing expectations can no longer be fulfilled. The sense of feeling cheated, disappointed, and bereft that is likely to arise for a woman in this situation must be anticipated, recognized, acknowledged, and forestalled when possible by those caring for her. Women who have to change track must be afforded the time, space, and support to explore the meaning of the change, to fully mourn what they lose because of it, and to recapture their losses to the greatest extent possible.

The findings reported in this article highlight the need for maternity services to adopt a family-focused approach rather than a procedure-centered approach in caring for women who must be scheduled for cesarean section. Referring to scheduled cesarean section as a 
unique and special birth event rather than a routine surgical intervention, for example, may reduce the fear that the procedure has been found in this study to engender in women.

As mentioned earlier, transformational trustworthiness of the study was evidenced when, having heard the findings, the research site subsequently implemented three initiatives aimed at enabling women who have no option but to undergo elective cesarean section for medical reasons to retain a sense of control and participation in their birth experience. These initiatives, which could be readily adopted in other settings included adding a "planned cesarean section" birth preparation day to the existing antenatal education program, providing the opportunity to "tour" the operating department (as the chance to tour the labor and birth suite is provided to women who are anticipating a vaginal birth), and developing an elective cesarean section birth plan pro forma for women to complete, discuss antenatally, and take with them to the operating room on the day of their baby's birth.

\section{NOTE}

1. "Birthrites: Healing After Caesarean Inc" is a notfor-profit community group run by and for women who have had, are having, or want to know more about caesarean section. The group also provides support and resources to women wanting to pursue vaginal birth after caesarean section (VBAC).

\section{REFERENCES}

Adewuya, A. O., Ologun, Y. A., \& Ibigami, O. S. (2006). Posttraumatic stress disorder after childbirth in Nigerian women: Relevence and risk factors. British Journal of Obstetrics and Gynaecology, 113(3), 284-288.

Bayes, S., \& Dufton, C. (2008, September). Initiating change in the operating theatre. Paper presented at the National Caesarean Awareness Day: Getting clear about fear, Perth, Western Australia.

Bayes, S., Dufton, C., \& Nunan, H. (2009, February). Improving women's experience of scheduled caesarean section. Paper presented at the Improving the Delivery of Maternity Care: Sharing the Lessons Learnt, Perth, Australia.

Bayes, S., Fenwick, J., \& Hauck, Y. (2007, September). Above and beyond the green drape: Non-participant observations of women and the theatre environment during elective caesarean sections performed for medical reasons. Paper presented at the "Big, Bold and Beautiful": The 15th
Biennial Australian College of Midwives' Conference, Canberra, Australian Capital Territory.

Bayes, S., Fenwick, J., \& Hauck, Y. (2008, June). Western Australian women's experience of a medically-necessary caesarean section scheduled in pregnancy: Emerging findings from a grounded theory study. Paper presented at the International Confederation of Midwives' Congress, Glasgow, Scotland.

Betrán, A. P., Merialdi, M., Lauer, J. A., Bing-Shun, W., Thomas, J., Van Look, P., \& Wagner, M. (2007). Rates of caesarean section: Analysis of global, regional and national estimates. Paediatric Perinatal Epidemiology, 21(2), 98-113.

Brown, S., \& Lumley, J. (1998). Maternal health after childbirth: Results of an Australian population-based survey. British Journal of Obstetrics and Gynaecology, 105(2), 156-161.

Callister, L. C., Holt, S. T., \& Kuhre, M. W. (2010). Giving birth: The voices of Australian women. Journal of Perinatal and Neonatal Nursing, 24(2), 128-136.

Carpenter Rinaldi, D. (1995). Grounded theory research approach. In H. J. Streubert \& D. Carpenter Rinaldi (Eds.), Qualitative research in nursing: Advancing the humanistic imperative (pp. 145-161). Philadelphia, PA: Lippincott.

Cho, J., \& Trent, A. (2006). Validity in qualitative research. Qualitative Research, 6, 319-340.

Christiaens, W., \& Bracke, P. (2007). Assessment of social psychological determinants of satisfaction with childbirth in a cross-national perspective. BMC Pregnancy and Childbirth, 7, 26. Retrieved from http://www. biomedcentral.com/1471-2393/7/26

De Oliveira, S. M., Riesco, M. L., Miya, C. F., \& Vidotto, P. (2002). Type of delivery: Women's expectations. Revisto Latino-Americana de Enfermagem, 10(5), 667-674.

Denzin, N. K. (1989). The research act: A theoretical introduction to sociological methods (3rd ed.). New Jersey, NJ: Prentice Hall.

Domingues, R. M., Santos, E. M., \& Leal, M. C. (2004). Aspects of women's satisfaction with childbirth care in a maternity hospital in Rio de Janeiro. Cadernas de Saude Publica, (20, Suppl 1), S52-S62.

Fair, C. D., \& Morrison, T. E. (2011). The relationship between prenatal control, expectations, experienced control, and birth satisfaction among primiparous women. Midwifery, 28(1), 39-44.

Fenwick, J., Gamble, J., \& Hauck, Y. (2006). Reframing birth: A consequence of caesarean section for a selfselected group of western Australian women. Journal of Advanced Nursing, 56(2), 121-132.

Fenwick, J., Hauck, Y., Downie, J., \& Butt, J. (2005). The childbirth expectations of a self-selected cohort of western Australian women. Midwifery, 21(1), 23-35. 
Flint, N. (2005, November). FLI05040 Methodological conundrums: confessions of a latent grounded theorist. Paper presented at the "Creative Dissent: Constructive Solutions": The 19th Annual Conference of The Australian Association of Research in Education, Paramatta, New South Wales.

Fowles, E. R. (1998). Labor concerns of women two months after delivery. Birth, 25(4), 235-240.

Gamble, J., \& Creedy, D. (2001). Women's preference for a cesarean section: Incidence and associated factors. Birth, 28(2), 101-110.

Gamble, J., Creedy, D., McCourt, C., Weaver, J., \& Beake, S. (2001). A critique of the literature on women's request for caesarean section. Birth, 34(4), 331-340.

Glaser, B. (1978). Theoretical sensitivity: Advances in the methodology of grounded theory. Mill Valley, California: Sociology Press.

Glaser, B. (1998). Doing grounded theory: Issues and discussions. Mill Valley, California: Sociology Press.

Glaser, B., \& Strauss, A. L. (1967). The discovery of grounded theory: Strategies for qualitative research. New York, NY: Aldine de Gruyter.

Golafshani, N. (2003). Understanding reliability and validity in qualitative research. The Qualitative Report, 8(4), 597-607.

Goodman, P., Mackey, M. C., \& Tavakoli, A. S. (2004). Factors related to childbirth satisfaction. Journal of Advanced Nursing, 46(2), 212-219.

Harriott, E. M., Williams, T. V., \& Peterson, M. R. (2005). Childbearing in U. S. military hospitals: Dimensions of care affecting women's perceptions of quality and satisfaction. Birth, 32(1), 4-10.

Hay, D. F., Pawlby, S., Sharp, D., Asten, P., Mills, A., \& Kumar, R. (2001). Intellectual problems shown by 11-year-old children whose mothers had postnatal depression. Journal of Child Psychology and Psychiatry, 42(7), 871-889.

Herishanu-Gilutz, S., Shahar, G., Schattner, E., Kofman, O., \& Holcberg, G. (2009). On becoming a first-time mother after an emergency Caesarean section: A journey from alienation to symbolic adoption. Journal of Health Psychology, 14(7), 967-981.

Hodnett, E. D. (2002). Pain and women's satisfaction with the experience of childbirth: A systematic review. American Journal of Obstetrics and Gynecology, 186(Suppl. 5), S160-S172.

Howell-White, S. (1999). Birth alternatives: How women select childbirth care. Westport, CT: Greenwood Press.

Ip, W. Y., Chien, W. T., \& Chan, C. L. (2003). Childbirth expectations of Chinese first-time pregnant women. Journal of Advanced Nursing, 42(2), 151-158.
Kao, B., Gau, M., Wu, S., Kuo, B., \& Lee, T. Y. (2004). A comparative study of expectant parents' childbirth expectations. Journal of Nursing Research, 12(3), 191-201.

Lavender, T., Walkinshaw, S. A., \& Walton, I. (1999). A prospective study of women's views of factors contributing to a positive birth experience. Midwifery, 15(1), 40-46.

Laws, P. J., Li, Z., \& Sullivan, E. A. (2011). Australia's Mothers and Babies 2008. Perinatal statistics series no. 24. Retrieved from www.aihw.gov.au/WorkArea/ DownloadAsset.aspx?id=6442472762

Lundgren, I. (2005). Swedish women's experience of childbirth 2 years after birth. Midwifery, 21(4), 346-254.

Luyben, A. G., \& Fleming, V. E. M. (2005). Women's needs from antenatal care in three European countries. Midwifery, 21, 212-223.

Maggioni, C., Margola, D., \& Filippi, F. (2006). PTSD risk factors and expectations among women having a baby: A two-wave longitudinal study. Journal of Psychosomatic Obstetrics and Gynaecology, 27(2), 81-90.

Mazzoni, A., Althabe, F., Liu, N. H., Bonotti, M., Gibbons, L., Sánchez, A. J., Belizán, J. M. (2011). Women’s preference for caesarean section: A systematic review and meta-analysis of observational studies. British Journal of Obstetrics and Gynaecology, 118(4), 391-399.

McCourt, C., Weaver, J., Statham, H., Beake, S., Gamble, J., \& Creedy, D. (2007). Elective cesarean section and decision making: A critical review of the literature. Birth, 34 (1), 65-79.

Mercer, R., \& Marut, J. (1981). Comparative viewpoints: Cesarean versus vaginal childbirth. In D. D. Affonso (Ed.), Impact of Cesarean Childbirth (pp. 63-84). Philadelphia, PA: F. A. Davis Company.

Oweis, A., \& Abushaikha, L. (2004). Jordanian pregnant women's expectations of their first childbirth experience. International Journal of Nursing Practice, 10(6), 264-271.

Parkes, C. M. (1971). Psycho-social transitions: A field for study. Social Science and Medicine, 5(3), 101-115.

Parkes, C. M. (1993). Bereavement as a psychosocial transition: Processes of adaptation to change. In W. Stroebe \& R. O. Hanson (Eds.), Handbook of bereavement: Theory, research and intervention (pp. 91-101). Cambridge, United Kingdom: Cambridge University Press.

Parratt, J. (2002). The impact of childbirth experiences on women's sense of self: A review of the literature. Australian Journal of Midwifery, 15(4), 10-16.

Rijnders, M., Baston, H., Schönbeck, Y., van der Pal, K., Prins, M., Green, J., \& Buitendijk, S. (2008). Perinatal factors related to negative or positive recall of birth experience in women 3 years postpartum in the Netherlands. Birth, 35(2), 107-116. 
Rubin, R. (1976). Maternal tasks in pregnancy. Journal of Advanced Nursing, 1, 367-376.

Ryding, E. L., Wijma, K., \& Wijma, B. (1998). Experiences of emergency caesarean section: A phenomenological study of 53 women. Birth, 25(4), 246-251.

Saurel-Cubizolles, M. J., Romito, P., Lelong, N., \& Ancel, P. Y. (2000). Women's health after childbirth: A longitudinal study in France and Italy. British Journal of Obstetrics and Gynaecology, 107(10), 1202-1209.

Schneider, Z. (2002). An Australian study of women's experiences of their first pregnancy. Midwifery, 18, 238-249.

Sidani, S., \& Sechrest, L. (1996). Analysis and use of qualitative data. NIDA Research Monograph, 166, 292-309.

Simkin, P. (1991). Just another day in a woman's life? Women's long-term perceptions of their first birth perception. Part I. Birth, 18(4), 203-210.

Sinclair, A., \& Murray, L. (1998). Effects of postnatal depression on children's adjustment to school. British Journal of Psychiatry, 172, 58-63.

Soet, J. E., Brack, G. A., \& Dilorio, C. (2003). Prevalence and predictors of women's experience of psychological trauma during childbirth. Birth, 30(1), 36-46.

Somera, M. J., Feeley, N., \& Ciofani, L. (2010). Women's experience of an emergency caesarean birth. Journal of Clinical Nursing, 19(19-20), 2824-2831.
Vogt, W. P. (1993). Dictionary of statistics and methodology: A non-technical guide for social scientists. Newberry Park, CA: Sage.

Waldenström, U., Hildingsson, I., Rubertsson, C., \& Rådestad, I. (2004). A negative birth experience: Prevalence and risk factors in a national sample. Birth, 31(1), 17-27.

Wolf, Z. (2003). Exploring the audit trail for qualitative researchers. Nurse Educator, 28(4), 175-178.

Correspondence regarding this article should be directed to Sara Bayes, PhD, RM, Nottingham University Business School, Jubilee Campus, Nottingham, England, UK NG8 1BB. E-mail: sara.bayes@nottingham.ac.uk

Sara Bayes, PhD, RM, Nottingham University Business School, Nottingham, England.

Jennifer Fenwick, PhD, RM, School of Nursing and Midwifery, Maternity and Family, Griffith University and the Research Center for Clinical and Community Practice Innovation (RCCCPI) at Griffith Health, Queensland, Australia.

Yvonne Hauck, PhD, RM, King Edward Memorial Hospital and the School of Nursing and Midwifery, Curtin Health Innovation Research Institute (CHIRI), Curtin University, Perth, Western Australia. 